\title{
Study on Tensile Properties of Weft Knitted Float Stitch
}

\section{Fabric Reinforced Composites}

\author{
Zhigang Qin ${ }^{1,2}$ a,$Y a n m a o ~ X i a a^{1, b}$ \\ ${ }^{1}$ College of Textiles \& Garments, Hebei University of Science and Technology, \\ Shijiazhuang, Hebei, 050018, China \\ ${ }^{2}$ Hebei Research Center of Engineering and Technology for Textile and Clothes, \\ Shijiazhuang, Hebei, 050018, China \\ azhigang_qin@126.com, ${ }^{\mathrm{b}}$ 627920410@qq.com
}

\begin{abstract}
Keywords:Tensile properties, Glass continuous-filament yarn, Weft knitted fabric, Float stitch, Composite.

Abstract.Weft knitted fabrics and their reinforced composites have good extensibility, high production efficiency, good formability, impact resistance and low production costs. The two kinds of weft knitted float stitch fabrics are made of glass continuous filament yarns, and were knitted on computerized flat knitting machine. The weft knitted fabric/epoxy resin composites are produced by manual molding technology. The tensile properties of composites in the course, wale and diagonal directions are tested on the universal material testing machine. The results show that the tensile stress/strain curves of the composites were nonlinear. The tensile properties of the composites are obvious anisotropy. The tensile strengths and elastic modulus of the weft knitting composites depend on fabric density and structure. The amount of resin coated also has some effect on the tensile properties.
\end{abstract}

\section{Introduction}

In the development of the textile composites, the properties of glass fiber yarn have the big stiffness and the small breaking elongation, thus increasing the difficulty of the glass fiber in the application of the knitting. But low price makes the glass fiber widely used [1-3]. Glass fiber weft knitted fabrics and their reinforced composites were valued by the people until recent years [4]. People study weft knitted fabrics and their reinforced composites because they have several obvious advantages over the other fabrics. They have high productivity, low fabrication cost, high fracture strength, impact resistance and ease of molding, especially suitable for the manufacture net shape/near-net-shape preforms and components of complex shape [5]. More and more weft knitted fabric reinforced composites are applied in space navigation, automotive, machinery, sports and medical instruments because of its unique performance [6].

\section{The Weft Knitted Float Stitch Fabrics and Their Structural Parameters}

Two kinds of the weft knitted float stitch fabrics were knitted on computerized flat knitting machine by using the SC $8-24 \times 3 Z 80$ glass continuous-filament yarns. The knitting diagram and the images of technical face and back of Fabric A are shown in Fig.1. The wale density of front and back of the fabric $A$ is 2:3. Fig. 2 shows the knitting diagram and the images of technical face of Fabric B .The 
face and back of the fabric have the same organizational structure.

Table1 gives the structural parameters of the two types of weft knitted fabrics.

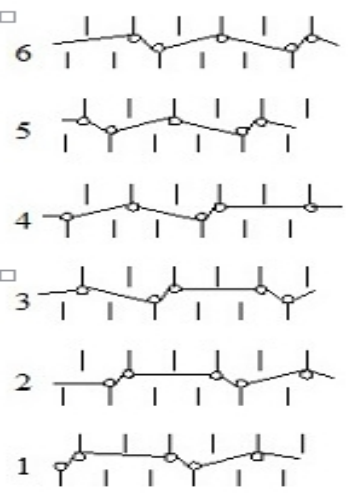

(a)The knitting diagram

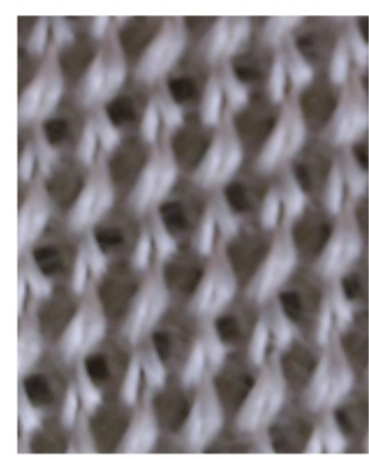

(b)The technical face

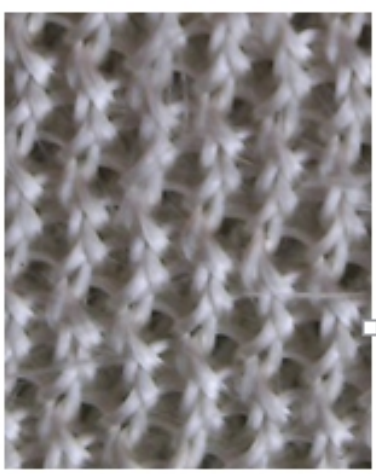

(c)The technical back

Fig. 1 The knitting diagram and the images of technical face and back of Fabric A
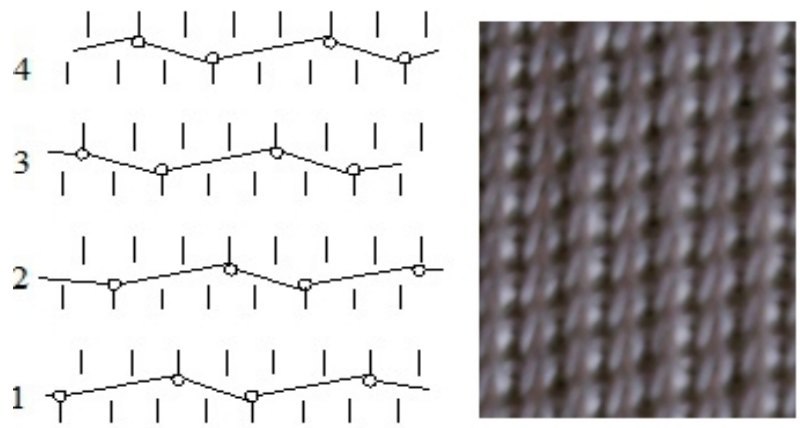

(a) The knitting diagram

(b) The image of technical face

Fig.2 The knitting diagram and the images of technical face and back of Fabric B

Table 1 The structural parameters of the weft knitted fabrics

\begin{tabular}{ccccccc}
\hline & \multicolumn{2}{c}{$\begin{array}{c}\text { Course Density } \\
(\mathrm{c} / \mathrm{cm})\end{array}$} & \multicolumn{2}{c}{$\begin{array}{c}\text { Wale density } \\
(\mathrm{w} / \mathrm{cm})\end{array}$} & $\begin{array}{c}\text { Areal } \\
\text { Fabrics }\end{array}$ & $\begin{array}{c}\text { Thickness } \\
\left./ \mathrm{m}^{2}\right)\end{array}$ \\
\cline { 2 - 5 } & $\begin{array}{c}\text { technical } \\
\text { face }\end{array}$ & $\begin{array}{c}\text { technical } \\
\text { back }\end{array}$ & $\begin{array}{c}\text { technical } \\
\text { face }\end{array}$ & $\begin{array}{c}\text { technical } \\
\text { back }\end{array}$ & & \\
\hline A & 33 & 32 & 33 & 45 & 259.7 & 2.14 \\
B & 40 & 40 & 40 & 40 & 315.8 & 2.39 \\
\hline
\end{tabular}

\section{The Production of Composite specimens}

The Specimens of composite samples used for the experiment were manufactured from two kinds of glass fiber weft knitted fabric and E-44 epoxy resin by manual molding technology.The curing agent was 650 low molecular polyamide resins. Table2 shows the basic parameters of composite specimens.

Table 2 The parameters of composite specimens

\begin{tabular}{ccc}
\hline specimens & Thickness $(\mathrm{mm})$ & Fiber volume fraction $(\%)$ \\
\hline $\mathrm{A}$ & 3 & 13.0719 \\
$\mathrm{~B}$ & 3 & 19.6078 \\
\hline
\end{tabular}




\section{Tensile Experiments}

The tensile properties of composite specimens were tested on the suns UTM5105 automatic testing machine in three directions that are the course $\left(0^{\circ}\right)$, wale $\left(90^{\circ}\right)$ and diagonal $\left(45^{\circ}\right)$ directions of weft knitted fabric composite specimens. The composite specimens were prepared and the tests were carried out according to Fiber-reinforced plastics composites-Determination of tensile properties (GB/T1447-2005).

\section{Results and Discussion}

The tensile stress/strain curves for two types of composite specimens are shown in Fig.3 (a) and (b).The tensile parameters of two kinds of weft knitted fabric reinforced composites are summarized in Table 3.

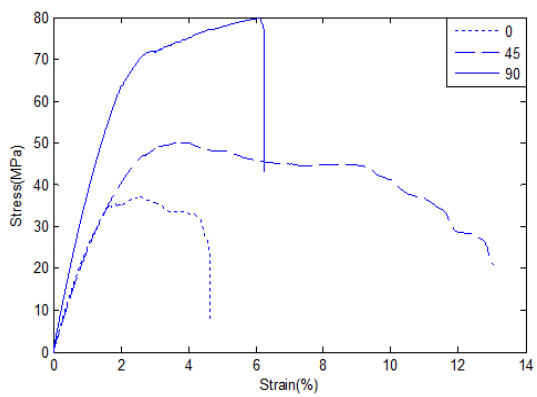

(a) Specimen A

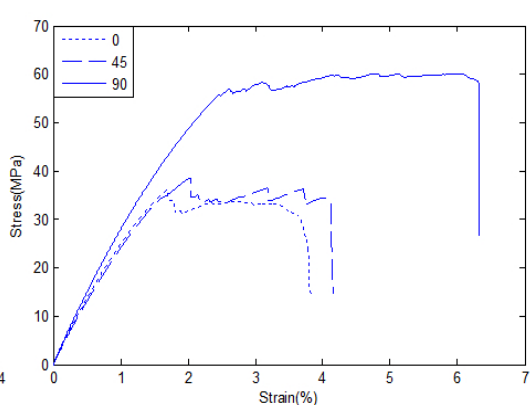

(b) Specimen B

Fig. 3 Tensile stress/strain curves for composite specimens

Table 3 The tensile parameters of warp knitted fabric reinforced composites

\begin{tabular}{ccccc}
\hline Specimens & $\begin{array}{c}\text { Fiber volume } \\
\text { fraction (\%) }\end{array}$ & $\begin{array}{c}\text { Loading direction } \\
\text { Strength }\end{array}$ & $\begin{array}{c}\text { Strength } \\
(\mathrm{MPa})\end{array}$ & $\begin{array}{c}\text { Modulus } \\
(\mathrm{GPa})\end{array}$ \\
\hline $\mathrm{A}$ & 13.0719 & $0^{\circ}$ & 36.0880 & 2.9581 \\
& & $45^{\circ}$ & 38.6137 & 2.7637 \\
& & $90^{\circ}$ & 60.1885 & 3.1485 \\
\hline $\mathrm{B}$ & 19.6078 & $0^{\circ}$ & 36.9988 & 2.9422 \\
& & $45^{\circ}$ & 50.0790 & 2.5581 \\
& & $90^{\circ}$ & 79.7380 & 4.3288 \\
\hline
\end{tabular}

From the Fig.3, it can be seen that in the initial stage, the tensile stress/strain curves of the composites were close to linear, but with the increase of strain, the curve shape was nonlinear and similar to the parabola shape. Before the material fracture, there is a phenomenon of jitter in some tension curves. Along with the tensile test, the surface of the sample appeared white spot and cracks, and with the sound of cracking, then the specimen fracture.The tensile curves of the composite Specimen A and B have a similar variation.

From the table 3, it can be seen that the tensile strength values of them are the highest in the wale direction, the lowest in the course direction. Because in the transverse tensile, the needle loop and sinker loop can produce a small amount of bending and straightening, yarn strength is not good to use. While in the longitudinal tensile, the orientation of the loop legs and the direction of force are the same direction. The number of yarns that bear the tensile force in the longitudinal tensile is more than that of the transverse tensile. Also, the tensile modulus of them is the highest in the wale direction, the lowest in the diagonal direction. It shows the diagonal direction is easier to 
deformation. Because of the appearance of fabric A and fabric B is a diagonal effect, under the influence of large load, the material is stretched along the direction of the texture. The tensile strength of the sample B was greater than the sample A. In the wale direction, the tensile modulus of the sample B was larger than that of the sample A. In the course direction, the tensile modulus of the two is close to each other. But in diagonal direction, the tensile modulus of the sample A was larger than that of the sample B.

\section{Conclusions}

By analyzing the tensile tests, tensile stress/strain curves were linear in the beginning, but when the strain exceeds a certain value, the tensile stress/strain curves were beginning to become nonlinear. The tensile strength values and elastic modulus of two weft knitted fabric reinforced composites were the highest in wale direction. Fabric structures have a certain influence on the tensile properties of the composites. The more longer floats were, the better tensile properties of composites. When oblique effect was more obvious, tensile modulus had become worse along the diagonal. The amount of resin coated also has some effect on the tensile properties.

\section{Acknowledgements}

This work was financially supported by the Foundation (2014PT03) of Hebei University of Science and Technology.

\section{References}

[1] Hearle J W S.Textiles for composites: Textile Horizons. Jan. 15(1995), p.11

[2] Long HaiRu. Tensile Properties of Weft Knitted Fabric Reinforced Composites. Shanghai: Journal of Dong Hua University, 2001(01):97.

[3] Savci S, Curiskis J I, Pailthorpe MT: Knittability of glass fiber weft knitted performs for composites: Textile Res. Jan, 71(2001), p.1015

[4] Yanan Feng et al.The raw material and structure of weft knitted composites: Industrial textiles.Vol. 10(2013), p.5

[5] Lau K W, Dias T. Knittability of high-modulus yarns: Text Inst. Feb. 85(1994), p.173

[6] Hong Hu. Application of weft knitted structure in composite materials: Donghua University. 2006, P55 